\title{
Long-Term Modelling Reveals Contrasting Population Trends Among North American Hummingbirds
}

\section{Simon G. English}

Environment and Climate Change Canada, Pacific Wildlife Research Centre

Christine A. Bishop ( $\square$ christine.bishop@canada.ca )

Environment and Climate Change Canada, Pacific Wildlife Research Centre

\section{Scott Wilson}

Environment and Climate Change Canada, Pacific Wildlife Research Centre

Adam C. Smith

Environment and Climate Change Canada, National Wildlife Research Centre

\section{Research Article}

Keywords: Long-term, population, hummingbirds, ecological

Posted Date: April 29th, 2021

DOI: https://doi.org/10.21203/rs.3.rs-465047/v1

License: (a) (i) This work is licensed under a Creative Commons Attribution 4.0 International License.

Read Full License 


\title{
Long-term modelling reveals contrasting population trends among North American hummingbirds
}

\author{
Simon G. English ${ }^{1}$, Christine A. Bishop ${ }^{1, *}$, Scott Wilson ${ }^{1}$, and Adam C. Smith ${ }^{2}$ \\ ${ }^{1}$ Environment and Climate Change Canada, Wildlife Research Division, Pacific Wildlife Research Centre, 5421 \\ Robertson Road, Delta, BC,4V4K 3N2, Canada \\ ${ }^{2}$ Environment and Climate Change Canada, Wildlife Research Division, National Wildlife Research Centre, 1125 \\ Colonel By Drive, Ottawa, ON, K1S 5B6, Canada \\ *christine.bishop@canada.ca
}

\section{ABSTRACT}

As pollinators, hummingbirds play a critical role for both the function of ecological communities and in providing ecosystem services for people. To examine the conservation status of North American hummingbirds, we analyzed Breeding Bird Survey data for 8 species and 3 genera for which there was sufficient survey coverage from 1970 to 2019 (long-term) and from 2009 to 2019 (short-term, approximately three generations). Among the Selasphorus genus, Allen's, rufous, and broad-tailed hummingbirds have declined since 1970, and the rate of decline increased from 2009 to 2019. In a reversal of the trends

10 from the past half-century, ruby-throated hummingbirds of Eastern North America have declined since approximately 2004 throughout most of the species' breeding range. In contrast, Anna's hummingbird populations have increased dramatically since 1970 in their range in western North America. This increase is most exaggerated in Canada, related to a northern range expansion. Our results highlight contrasting population trends across species and provide an important first step to address declines, most notably among species in the Selasphorus and Archilochus genera. Our geographic modelling also emphasizes the need to prioritize regions of conservation interest in the breeding and wintering ranges of hummingbirds.

\section{Introduction}

We have reached a turning point in the modern era for biodiversity loss ${ }^{1}$. Human disturbance to habitat and climate change are the two greatest threats to biodiversity of our time ${ }^{2,3}$. Nearly $60 \%$ of all bird species in North America are in decline, with a loss of almost $30 \%$ of birds since $1970^{4}$ and others projected to become extinct within the next 30 years ${ }^{5}$. Evidently, the widespread risk of diversity loss is substantial, although resources allocated to conservation are not. Here we report on an underrepresented family of birds in the literature that may be at the forefront of these declines: the hummingbirds (Trochilidae).

Hummingbirds are an ecologically important family of birds in North America, pollinating at least 184 known plant species through co-evolution with the plants that provide nectar to fuel their high-energy flight ${ }^{6-8}$. Hummingbirds are among the most rapidly diversifying clades of birds in the world, due in part to the diversity of ecological niches they exploit ${ }^{9}$. As such, they possess diverse phenological and life-history characteristics. For instance, many of the North American hummingbirds are migratory ${ }^{10}$, a characteristic that makes them especially vulnerable to the impacts of climate change and human disturbance to habitat ${ }^{11}$. In contrast, urbanization and changing climate may have relieved environmental pressures for other species, particularly non-migratory hummingbirds that benefit from year-round access to introduced plant species and supplemental feeders $^{12,13}$. Therefore, as human activity and climate change alter ecoregions differently ${ }^{14,15}$, hummingbird species may also be impacted at different rates.

Among the 14 species of North American hummingbirds that commonly occur north of Mexico ${ }^{16}$, some have experienced range transformations, while others have shown population declines since the 1970s when continental monitoring began with programs such as the North American Breeding Bird Survey (BBS) ${ }^{10,13}$. The family as a whole has experienced significant population declines ${ }^{4}$, although species including the ruby-throated hummingbird (A. colubris) and the Anna's hummingbird ( $C$. anna) have previously shown periods of population growth over the last 50 years ${ }^{10,12}$. We analyzed Breeding Bird Survey (BBS) data to examine range-wide and regional population trends for 8 species in 3 genera: Allen's hummingbirds (Selasphorus sasin), rufous hummingbirds (Selasphorus rufus), broad-tailed hummingbirds (Selasphorus platycercus), calliope hummingbirds (Selasphorus calliope), black-chinned hummingbirds (Archilochus alexandri), ruby-throated hummingbirds (Archilochus colubris), Anna's hummingbirds (Calypte anna), and Costa's hummingbirds (Calypte costae). Species in the Archilochus and Selasphorus genera are medium-to-long-distance migrants with a resident subspecies of the Allen's hummingbird expanding its range ${ }^{13}$. Both Calypte species are resident to short-distance migrants. 
We analyzed the period from 1970 to 2019 and contrast these results with short-term analyses for the period from 2009 to 2019 to gain insight into population changes occurring over approximately three generations. We also focus on regional trends of each species to examine spatial variation in trends across the range of each species. Among the hummingbirds we analyzed, diverse life-history characteristics are represented, from resident species to long-distance migrants, urbanized species and species whose habitat is largely limited to shrubsteppe or forested landscapes, as well as species with diverse breeding phenologies. We consider how these different characteristics may relate to the population trends observed in our dataset.

\section{Results}

We modelled hummingbird populations in North America from BBS data from 1970-2019 for long-term population trends and from 2009-2019 for short-term trends (Figure 1). We analyzed 8 species in 3 genera for which there was sufficient BBS coverage, where $n_{l t}$ is the number of BBS routes included in long-term analyses and $n_{s t}$ is the number of BBS routes included in short-term analyses: calliope hummingbirds (Selasphorus calliope; $n_{l t}=223 ; n_{s t}=193$ ), broad-tailed hummingbirds (Selasphorus platycercus; $n_{l t}=303 ; n_{s t}=267$ ), rufous hummingbirds (Selasphorus rufus; $n_{l t}=408 ; n_{s t}=348$ ), and Allen's hummingbirds (Selasphorus sasin; $n_{l t}=59 ; n_{s t}=50$ ), black-chinned hummingbirds (Archilochus alexandri; $n_{l t}=471$; $n_{s t}=399$ ), ruby-throated hummingbirds (Archilochus colubris; $n_{l t}=2469 ; n_{s t}=2123$ ), Anna's hummingbirds (Calypte anna; $n_{l t}=266 ; n_{s t}=223$ ), Costa's hummingbirds (Calypte costae; $n_{l t}=97 ; n_{s t}=73$ ).

Three of the four species in the Selasphorus genus have declined since 1970, while the fourth species, the calliope hummingbird, has remained relatively stable (Figure 2). From 1970 to 2019, Allen's hummingbirds declined by $-88 \%$ (CI: $-95 \%$ to $-76 \%$ ) at an average annual rate of $-4.3 \% \mathrm{yr}^{-1}$ (CI: $-5.8 \% \mathrm{yr}^{-1}$ to $-2.8 \% \mathrm{yr}^{-1}$ ) (Figure 1). Allen's hummingbirds suffered a dramatically steepened short-term decline at nearly a two-fold greater rate than over the past 50 years $\left(-7.9 \% \mathrm{yr}^{-1}\right.$; CI: $-12.4 \% \mathrm{yr}^{-1}$ to $-3.6 \% \mathrm{yr}^{-1}$ ) throughout regions of their range with sufficient coverage to estimate trends (Figure S1). From 1970 to 2019 , rufous hummingbird populations declined by $-65 \%$ (CI: $-72 \%$ to $-56 \%$ ) at $-2.1 \% \mathrm{yr}^{-1}$ (CI: $-2.6 \% \mathrm{yr}^{-1}$ to $-1.7 \% \mathrm{yr}^{-1}$ ) and this rate of change has also accelerated by nearly two-fold to $-4.1 \% \mathrm{yr}^{-1}$ (CI: $-5.5 \% \mathrm{yr}^{-1}$ to $-2.7 \% \mathrm{yr}^{-1}$ ) (Figure 1). These trends appear to be most dramatic on the Pacific Coast of the rufous hummingbird's range (Figure S2). Trend analyses of broad-tailed hummingbirds revealed a population loss of $-37 \%$ (CI: $-52 \%$ to $-19 \%$ ) at $-0.95 \% \mathrm{yr}^{-1}$ (CI: $-1.5 \% \mathrm{yr}^{-1}$ to $-0.42 \% \mathrm{yr}^{-1}$ ) in the long-term, and $-2.4 \% \mathrm{yr}^{-1}\left(\mathrm{CI}:-3.4 \% \mathrm{yr}^{-1}\right.$ to $\left.-1.3 \% \mathrm{yr}^{-1}\right)$ in the short-term (Figure 1). Declines appear most significant in the southern extent of their range (Figure S3). Calliope populations are not changing significantly, either in the long-term $\left(-0.057 \% \mathrm{yr}^{-1}\right.$; CI: $-0.87 \% \mathrm{yr}^{-1}$ to $\left.0.80 \% \mathrm{yr}^{-1}\right)$ or the short-term $\left(-0.82 \% \mathrm{yr}^{-1}\right.$; CI: $-3.1 \% \mathrm{yr}^{-1}$ to $\left.1.6 \% \mathrm{yr}^{-1}\right)$ (Figure S4).

Continent-wide populations of both species in the Archilochus genus show increases over the long-term but declines from 2009 to 2019. From 1970 to 2019, the continent-wide black-chinned hummingbird population increased by $52 \%$ (CI: $16 \%$ to $98 \%$ ) at a rate of $0.86 \% \mathrm{yr}^{-1}$ (CI: $0.31 \% \mathrm{yr}^{-1}$ to $1.40 \% \mathrm{yr}^{-1}$ ). Ruby-throated hummingbird population increased by $79 \%$ (CI: $65 \%$ to $95 \%$ ) at a rate of $1.2 \% \mathrm{yr}^{-1}$ (CI: $1.0 \% \mathrm{yr}^{-1}$ to $1.4 \% \mathrm{yr}^{-1}$ ) since 1970 (Figure 1). The short-term population trends from 2009 to 2019 were relatively stable for black-chinned hummingbirds $\left(-0.75 \% \mathrm{yr}^{-1}\right.$; CI: $-2.5 \% \mathrm{yr}^{-1}$ to $\left.1.0 \% \mathrm{yr}^{-1}\right)$ although there appears to be a signal of moderate declines throughout most of the species range (Figure S5). Trends also reversed for ruby-throated hummingbirds, where over a 10 -year period, the continent-wide population decreased by $-9.5 \%$ (CI: $-15 \%$ to $-3.6 \%$ ) at an average rate of $-0.99 \% \mathrm{yr}^{-1}$ (CI: $-1.6 \% \mathrm{yr}^{-1}$ to $-0.36 \% \mathrm{yr}^{-1}$ ) throughout the breeding range (Figure 3, S6). This trend is more dramatic when estimated over the full 15-year period of decline. The average annual rate of decline from 2004 to 2019, ruby-throated hummingbirds in North American declined by an estimated $17 \%$ (CI: $-22 \%$ to $-10 \%)$ at an average annual rate of $-1.20 \% \mathrm{yr}^{-1}\left(\mathrm{CI}:-1.7 \% \mathrm{yr}^{-1}\right.$ to $-0.73 \% \mathrm{yr}^{-1}$.

Continent-wide population levels of the Calypte genus have increased in the case of Anna's Hummingbird or remained relatively stable in the case of Costa's hummingbirds (Figure 4). Anna's hummingbirds increased from 1970 to 2019 at a rate of $2.7 \% \mathrm{yr}^{-1}$ (CI: $2.1 \% \mathrm{yr}^{-1}$ to $3.3 \% \mathrm{yr}^{-1}$ ). This trend steepened in the short-term $\left(3.5 \% \mathrm{yr}^{-1}\right.$; CI: $1.5 \% \mathrm{yr}^{-1}$ to $\left.5.5 \% \mathrm{yr}^{-1}\right)$, and was most dramatic in the northern and western extent of the species' current range (Figure S7). Continent-wide Costa's hummingbird populations did not change significantly in our long-term $\left(0.30 \% \mathrm{yr}^{-1} ; \mathrm{CI}:-1.1 \% \mathrm{yr}^{-1}\right.$ to $\left.1.9 \% \mathrm{yr}^{-1}\right)$ or shortterm $\left(-1.0 \% \mathrm{yr}^{-1}\right.$; CI: $-4.9 \% \mathrm{yr}^{-1}$ to $\left.3.9 \% \mathrm{yr}^{-1}\right)$ trend analyses. Uncertainty on Costa's hummingbird trend analyses are relatively large (Figure 1), and may impact our ability to detect a significant signal of population decline reflected across the majority of their range (Figure S8). 

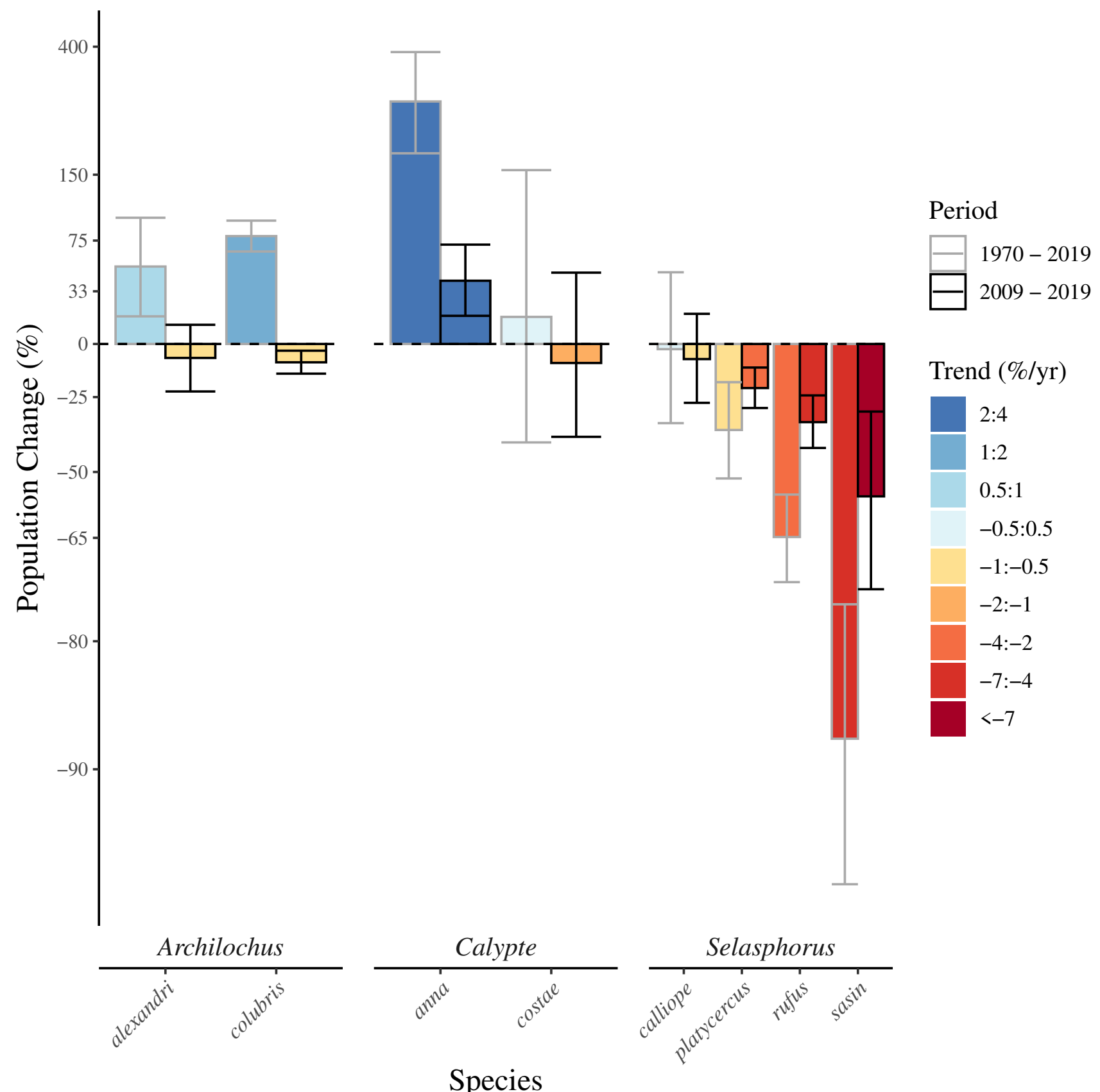

Figure 1. Percent change in hummingbird populations across North America. Vertical axes scale to symmetry on the log-scale to accurately represent the percent change necessary for a population to recover to initial size at the beginning of the period. Column colours scaled to rate of change where darker hues reflect a greater rate of change. Errors shown are the upper and lower bounds of $90 \%$ credible-intervals. 


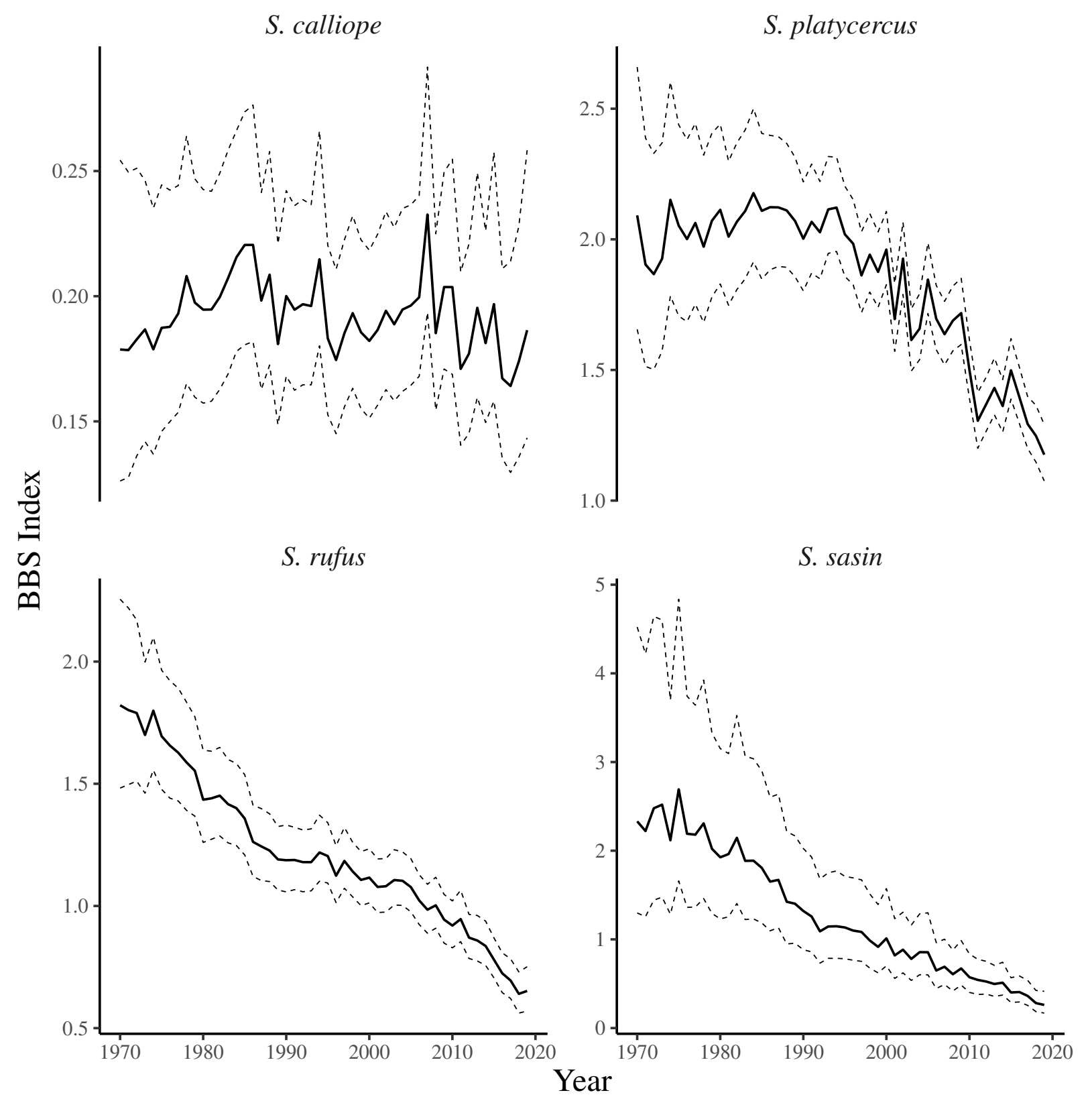

Figure 2. Breeding Bird Survey indices for North American hummingbirds in the Selasphorus genus from 1970 to 2019. Dashed lines represent upper and lower bounds of the $90 \%$ credible-interval. 


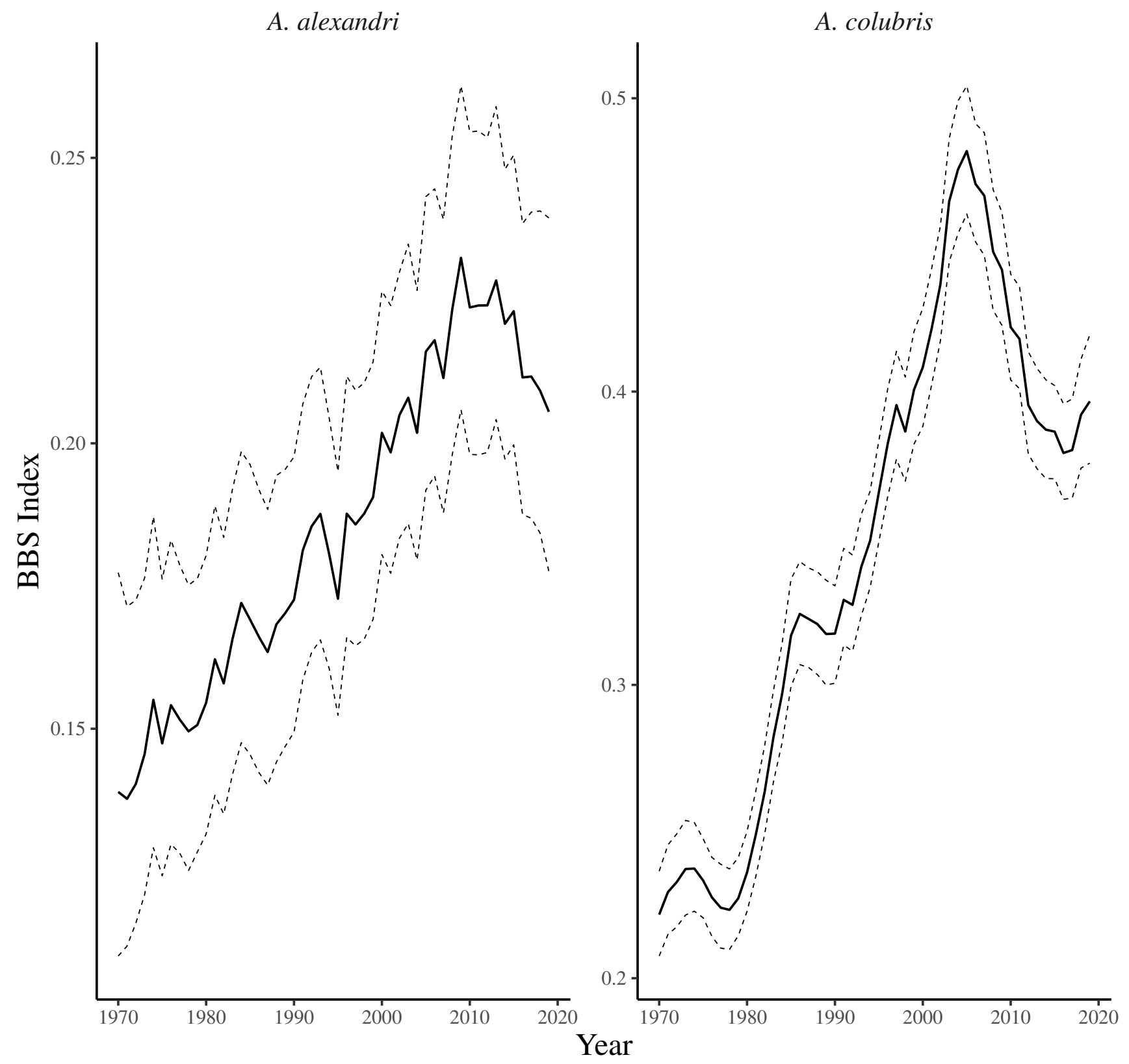

Figure 3. Breeding Bird Survey indices for North American hummingbirds in the Archilochus genus from 1970 to 2019. Dashed lines represent upper and lower bounds of the $90 \%$ credible-interval. 


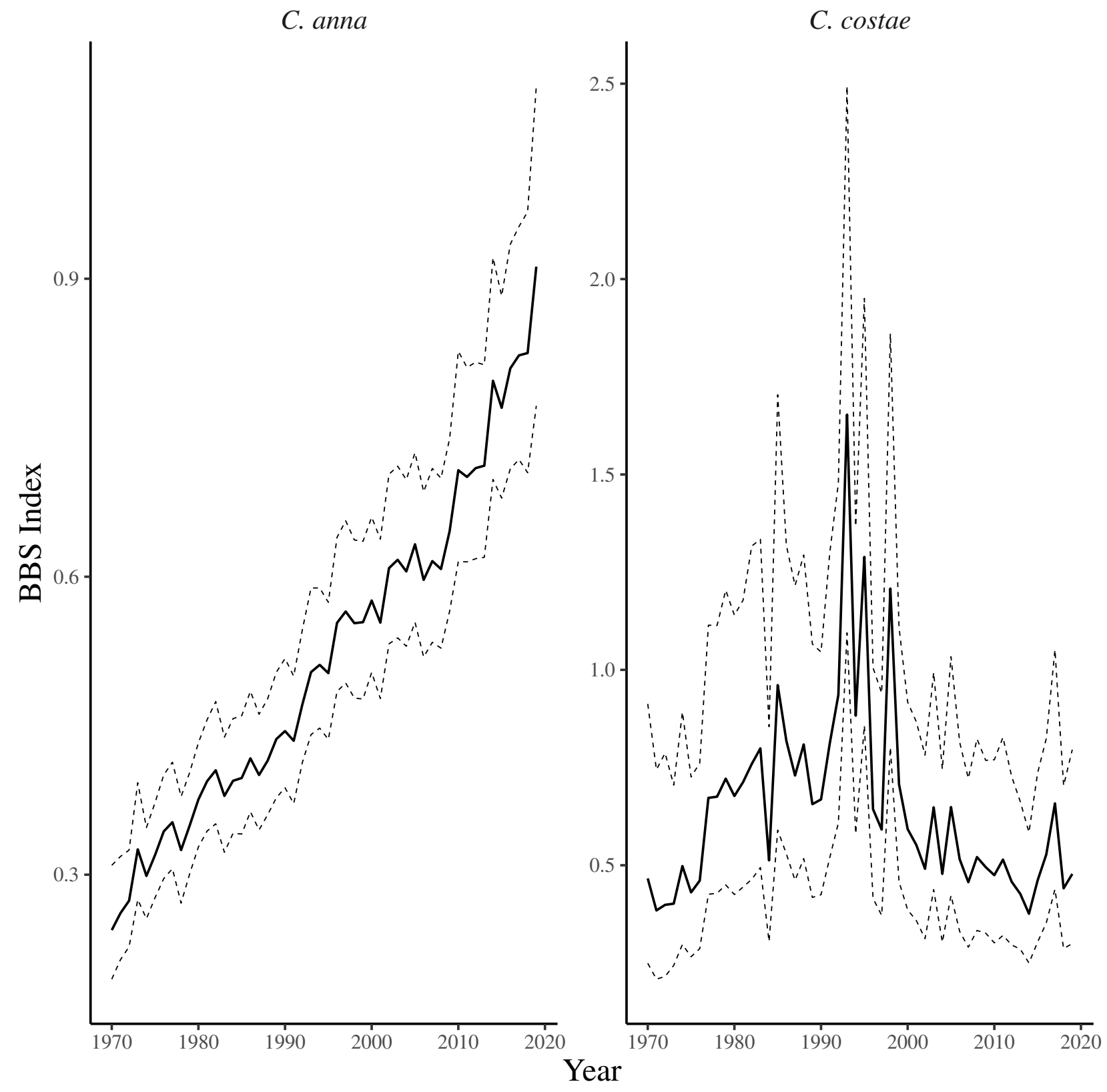

Figure 4. Breeding Bird Survey indices for North American hummingbirds in the Calypte genus from 1970 to 2019. Dashed lines represent upper and lower bounds of the $90 \%$ credible-interval.

\section{Discussion}

By conducting a family-level assessment of long-and short-term population trends we show the contrasting population trajectories among North American hummingbirds in a critical step towards understanding threats and potential conservation approaches for this ecological group. Our analyses revealed alarming population declines in the Selasphorus genus. Allen's, Rufous, and broad-tailed hummingbird declines have all accelerated over the last three generations to nearly double the rate of decline over the previous half-century. We also report previously undocumented declines of Eastern North America's most common hummingbird: the ruby-throated hummingbird (Figure 3), where over a 15-year period, the continent-wide population decreased by $17 \%$ (Figure 1). This short-term decline contrasts the species' average population growth rate from 1970 to 2019 (Figure 1). In contrast, the Anna's hummingbird, a resident hummingbird in Western North America, has experienced dramatic 
population growth at an accelerating rate in the last decade (Figure 1). Anna's hummingbird populations have increased significantly in the USA but most extremely in the expanding northern edge of their range in Canada (Figure S7), where the population increased at a rate of $20 \% \mathrm{yr}^{-1}$. The species was formerly rare in southern Canada even in the late 2000s but is now an abundant year-round resident in the Georgia Basin Ecosystem and commonly occurs as far north as southern Alaska.

The Selasphorus genus comprises medium-to-long distance migrants, including a resident population of Allen's hummingbirds in residential parts of California with a reportedly stable or perhaps growing population ${ }^{13}$. The cause of population decline for migratory Allen's, rufous and broad-tailed hummingbirds are still largely unknown. For migratory hummingbirds, plant phenology may provide cues on the quality of stopover sites ${ }^{17}$. A mismatch between hummingbird migration and plant phenology could contribute to decline in hummingbird populations, which are exacerbated among migratory species ${ }^{18}$. This kind of phenological mismatch is thought to occur for migratory rufous hummingbirds ${ }^{19}$. Furthermore, as natural habitats are converted into urban environments, invasive species may impact the quality of stopover sites and breeding grounds in remaining non-urban environments. An overabundance of deer can impact ecosystems through sustained overbrowsing of herbaceous cover and flowers ${ }^{20}$, thus precipitating detrimental changes to the woodlot and meadow habitats ${ }^{21,22}$. High-density white-tailed deer populations in wooded habitats in North America significantly reduced species richness and abundance of intermediate canopy nesting songbirds ${ }^{22}$, where most hummingbirds build their nests.

On the wintering grounds, the rufous hummingbird has reportedly experienced an expansion of wintering distribution, perhaps attributable to an increase in resources provided in gardens and genetic reprogramming of migratory orientation ${ }^{23}$; however, these hypotheses and the data on which they are based have not been updated or tested rigorously since their publication over 2 decades ago. Furthermore, the authors acknowledge the potential for a substantial observer bias, wherein more resources for identification of rufous hummingbirds promotes more frequent reporting as well as an unknown increase in supplemental resource provisioning ${ }^{23}$. Our data collected during the breeding season indicate similar declines in Canada and the USA for species which exist in both regions, both in the long-term and the short-term. While there is potential for a mismatch in breeding phenology, and thus detection, and surveying efforts ${ }^{24,25}$, an advancement of mean arrival date of several days is not likely to fully account for the drastic declines observed from northern and southern range limits even in our short-term analyses (Figure S2B), where Allen's hummingbirds lost $56 \%$ (CI: $31 \%$ to $73 \%$ ) of their population, while rufous hummingbirds lost $35 \%$ (CI: $24 \%$ to $43 \%$ ) since 2009 (Figure 1). Observation of declines for disparate populations in North America might also reflect threats on their non-breeding grounds ${ }^{26}$. For example, the wintering range of rufous, broad-tailed, and migratory Allen's populations all include montane forests in central Mexico where there is both recent and future projected habitat $\operatorname{loss}^{27}$. Threats to Selasphorus hummingbirds are still poorly known and future research to identify those threats and where they are most impactful should be considered a high priority.

The Archilochus hummingbird genus of medium-to-long distance migrants generally found at low elevation experienced population growth until approximately 2004. Trend maps for black-chinned hummingbirds from 2009 to 2019 reveal relatively stable or declining populations throughout most of the mapped region (Figure S5B). Ruby-throated hummingbirds show this same pattern, though with stronger declines over the last three generations (Figure S6B). Although data in the wintering range for these birds is largely unavailable, ruby-throated hummingbirds are arriving to breeding grounds up to $18 \mathrm{~d}$ earlier than they did historically in the northern parts of their range ${ }^{28}$. The considerable changes to the breeding phenology of ruby-throated hummingbirds during which the population increased and then declined suggests that a phenological mismatch with breeding surveys is unlikely, although this mechanism has been proposed to underlie the declines for Allen's and rufous hummingbirds ${ }^{13}$. Two possibilities for the recent reversal in population trends among black-chinned and ruby-throated hummingbirds that should be considered for further research include the impacts of wintering habitat $\operatorname{loss}^{26}$ and the impacts of widespread agrochemical exposure ${ }^{29-31}$.

In contrast to the general declines observed in the Selasphorus genus, Anna's Hummingbirds have experienced an ecological release putatively associated with climate change and supplemental resource provisioning by humans ${ }^{12,32}$. The increase in carrying capacity for Anna's hummingbirds in some Northern parts of their range are thought to be a result of increased nectar availability from feeders and eucalyptus trees, which bloom from October to April ${ }^{33}$, although eucalyptus availability would not apply in Canada. These additional resources alleviate the pressure of constricted nectar availability in winter months, when Anna's hummingbirds begin their breeding season, therefore increasing the potential for a second brood ${ }^{12,34}$. Anna's Hummingbirds may also possess physiological and behavioural adaptations not yet examined or quantified that allow them to tolerate the extreme cold weather in Canada. Moreover, the relatively early breeding season of Anna's hummingbirds gives them a considerable advantage over migratory species.

Estimating species population trends and population sizes using BBS data has drawn criticism because surveys along routes could potentially fail to transect productive habitats, or underestimate populations ${ }^{13,35,36}$. Still, the current and rapidly developing Bayesian statistical methods used to analyze these data have matured considerably in the past half-century to extract ecologically important information from species in regions with low survey coverage ${ }^{37-40}$. Furthermore, these are the most rigorous methods available because it is possible to quantify uncertainties in trend estimates ${ }^{41}$ and BBS monitoring still 
provides an unbiased estimate of the population trend in the location where the survey was conducted. The population declines observed in our BBS data show fairly symmetrical declines in the northern extent of the range of rufous and ruby-throated hummingbirds. This symmetrical decline throughout the range across long and short time periods would not be reflective of a phenological shift, as was suggested in a recent study using eBird data ${ }^{13}$. Understanding of the current limitations of these tools is essential for developing accurate trend estimates. Advances in other broad-scale monitoring programs such as eBird will soon allow for a comparative data set on hummingbird population trends. Monitoring programs combining citizen-science and BBS surveys have good potential to complement one another to identify and prioritize regions of conservation interest ${ }^{42,43}$ and provide more robust estimates over a broader region including the non-breeding grounds.

Hummingbird species across North America are clearly undergoing significant population changes. The strong declines reported here among species in the Selasphorus genus are of particular concern to biodiversity conservation efforts. Furthermore, the previously unreported declines of ruby-throated hummingbirds carry potentially important ecosystem-level consequences if left unaddressed, since this pollinator species alone fills it's ecological niche in Eastern North America. We propose future studies using citizen-science data collection to target regions of high conservation priority for ruby-throated hummingbirds and species in the Selasphorus genus, followed by BBS analyses to monitor population trends in ongoing efforts to conserve these essential pollinators of North America. More detailed studies are also needed to investigate potential drivers of decline, particularly the impacts of agrochemicals throughout the annual cycle and habitat loss on the non-breeding grounds.

\section{Methods}

\section{Breeding Bird Surveys}

BBS surveys have been conducted since 1966 and involve $\sim 40 \mathrm{~km}$ long transects consisting of 50 road-side point counts separated by $\sim 0.8 \mathrm{~km}^{10}$. Each route is surveyed by an expert once per year between late May and early July on fair weather days with the survey commencing approximately $0.5 \mathrm{~h}$ before sunrise. All species and individuals detected within a $400 \mathrm{~m}$ radius are recorded at each point count. For most analyses, abundance data is summed across all 50 points on each route to provide a single estimate of abundance per species per year. Our long-term trend analyses included data from 12-2469 routes, and short-term trend analyses included data from 12-2123 routes. BBS route coverage was sufficient for analysis of 8 of the 14 commonly occurring hummingbird species in the USA and Canada ${ }^{16}$. The species that were excluded have ranges that fall primarily in Mexico with only small peripheral populations in southern regions of California, Arizona and Texas where there was insufficient BBS coverage.

\section{Statistical analyses}

Population trends and trajectories were estimated using a Bayesian hierarchical Generalized Additive Model with Year Effects $(\mathrm{GAMYE})^{40}$ in $\mathrm{R}^{44}$. The survey-wide analyses were run during the annual analysis of the BBS data conducted by the Canadian Wildlife Service ${ }^{45}$, and additional summaries and maps were created with the R-package bbsBayes ${ }^{46}$. Point estimates for trends are calculated as the median of the posterior distribution generated from Markov-chain Monte-Carlo methods. Credible intervals (CI) for parameter estimates are computed as percentiles of the posterior distribution of parameters. CIs are reported for the interval spanning $90 \%$ of the posterior distribution, unless otherwise stated. Trends described for long-term data include the period from 1970 to 2019. Trends described for short-term data include the period from 2009 to 2019.

\section{Acknowledgements}

We thank the many volunteer surveyors who have contributed time and bird-identification expertise to the Breeding Bird Surveys. We also thank the BBS coordinators in Canada and the USA.

\section{Competing interests}

The authors declare no competing interests.

\section{Availability of materials and data}

BBS data and R scripts to analyze these data are provided by ACS on GitHub.

\section{References}

1. United Nations Environment Programme. Making Peace With Nature. Tech. Rep., United Nations Environment Programme (2021). 
2. Newbold, T. et al. Global effects of land use on local terrestrial biodiversity. Nature 520, 45-50, DOI: 10.1038/nature14324 (2015).

3. Urban, M. C. Accelerating extinction risk from climate change. Sci. (80-. ). 348, 571-573, DOI: 10.1126/science.aaa4984 (2015).

4. Rosenberg, K. V. et al. Decline of the North American avifauna. Sci. (80-. ). 366, 120-124, DOI: 10.1126/science.aaw1313 (2019).

5. Jetz, W., Wilcove, D. S. \& Dobson, A. P. Projected impacts of climate and land-use change on the global diversity of birds. PLoS Biol. 5, 1211-1219, DOI: 10.1371/journal.pbio.0050157 (2007).

6. Abrahamczyk, S. \& Renner, S. S. The temporal build-up of hummingbird/plant mutualisms in North America and temperate South America. BMC Evol. Biol. 15, DOI: 10.1186/s12862-015-0388-z (2015).

7. Grant, V. \& Grant, K. A. A Hummingbird-Pollinated Species of Boraginaceae in the Arizona Flora. Proc. Natl. Acad. Sci. 66, 917-919, DOI: 10.1073/pnas.66.3.917 (1970).

8. Ratto, F. et al. Global importance of vertebrate pollinators for plant reproductive success: a meta-analysis. Front. Ecol. Environ. 16, 82-90, DOI: 10.1002/fee.1763 (2018).

9. McGuire, J. A. et al. Molecular phylogenetics and the diversification of hummingbirds. Curr. Biol. 24, 910-916, DOI: 10.1016/j.cub.2014.03.016 (2014).

10. Sauer, J. R., Link, W. A., Fallon, J. E., Pardieck, K. L. \& Ziolkowski, D. J. The North American Breeding Bird Survey 1966-2011: Summary Analysis and Species Accounts. North Am. Fauna 79, 1-32, DOI: 10.3996/nafa.79.0001 (2013).

11. Bairlein, F. Migratory birds under threat. Sci. (80-. ). 354, 547-548, DOI: 10.1126/science.aah6647 (2016).

12. Battey, C. J. Ecological Release of the Anna's Hummingbird during a Northern Range Expansion. Am. Nat. 194, 306-315, DOI: $10.1086 / 704249$ (2019).

13. Clark, C. J. EBird records show substantial growth of the Allen's Hummingbird (Selasphorus sasin sedentarius) population in urban Southern California. Condor 119, 122-130, DOI: 10.1650/CONDOR-16-153.1 (2017).

14. Sleeter, B. M. et al. Land-cover change in the conterminous United States from 1973 to 2000. Glob. Environ. Chang. 23, 733-748, DOI: 10.1016/j.gloenvcha.2013.03.006 (2013).

15. Gallant, A. L., Loveland, T. R., Sohl, T. L. \& Napton, D. E. Using an ecoregion framework to analyze land-cover and land-use dynamics. Environ. Manag. 34 Suppl 1, DOI: 10.1007/s00267-003-0145-3 (2004).

16. Williamson, S. L. A Field Guide to Hummingbirds of North America (Peterson Field Guide Series) (Houghton Mifflin Company, Boston, 2002).

17. McGrath, L. J., van Riper III, C. \& Fontaine, J. J. Flower power: tree flowering phenology as a settlement cue for migrating birds. J. Anim. Ecol. 78, 22-30, DOI: 10.1111/j.1365-2656.2008.01464.x (2009).

18. Jones, T. \& Cresswell, W. The phenology mismatch hypothesis: are declines of migrant birds linked to uneven global climate change? J. Anim. Ecol. 79, 98-108, DOI: 10.1111/j.1365-2656.2009.01610.x (2010).

19. Courter, J. R. Changes In Spring Arrival Dates of Rufous Hummingbirds ( $<i>$ Selasphorus rufus $</ i>$ ) In Western North America In the Past Century. Wilson J. Ornithol. 129, 535-544, DOI: 10.1676/16-133.1 (2017).

20. Rooney, T. Deer impacts on forest ecosystems: a North American perspective. Forestry 74, 201-208, DOI: 10.1093/ forestry/74.3.201 (2001).

21. Côté, S. D., Rooney, T. P., Tremblay, J.-P., Dussault, C. \& Waller, D. M. Ecological Impacts of Deer Overabundance. Annu. Rev. Ecol. Evol. Syst. 35, 113-147, DOI: 10.2307/annurev.ecolsys.35.021103.30000006 (2004).

22. Decalesta, D. S. Effect of White-Tailed Deer on Songbirds within Managed Forests in Pennsylvania. J. Wildl. Manag. 58, 711-718 (1994).

23. Hill, G. E., Sargent, R. R. \& Sargent, M. B. Recent change in the winter distribution of Rufous Hummingbirds. Auk 115, 240-245, DOI: $10.2307 / 4089135$ (1998).

24. Lehikoinen, A. Climate change, phenology and species detectability in a monitoring scheme. Popul. Ecol. 55, 315-323, DOI: $10.1007 / \mathrm{s} 10144-012-0359-9$ (2013).

25. Massimino, D., Harris, S. J. \& Gillings, S. Phenological mismatch between breeding birds and their surveyors and implications for estimating population trends. J. Ornithol. 162, 143-154, DOI: 10.1007/s10336-020-01821-5 (2021). 
26. Wilson, S. et al. Prioritize diversity or declining species? Trade-offs and synergies in spatial planning for the conservation of migratory birds in the face of land cover change. Biol. Conserv. 239, 108285, DOI: 10.1016/j.biocon.2019.108285 (2019).

27. Toledo-Aceves, T., Meave, J. A., González-Espinosa, M. \& Ramírez-Marcial, N. Tropical montane cloud forests: Current threats and opportunities for their conservation and sustainable management in Mexico. J. Environ. Manag. 92, 974-981, DOI: 10.1016/j.jenvman.2010.11.007 (2011).

28. Courter, J. R., Johnson, R. J., Bridges, W. C. \& Hubbard, K. G. Assessing migration of Ruby-throated Hummingbirds ( $<\mathrm{i}>$ Archilochus colubris</i> ) at broad spatial and temporal scales. Auk 130,107-117, DOI: 10.1525/auk.2012.12058 (2013).

29. English, S. G. et al. Neonicotinoid pesticides exert metabolic effects on avian pollinators. Sci. Rep. 11, 2914, DOI: 10.1038/s41598-021-82470-3 (2021).

30. Bishop, C. A. et al. Determination of neonicotinoids and butenolide residues in avian and insect pollinators and their ambient environment in Western Canada (2017, 2018). Sci. Total. Environ. 737, 139386, DOI: 10.1016/j.scitotenv.2020.139386 (2020).

31. Graves, E. E. et al. Analysis of insecticide exposure in California hummingbirds using liquid chromatography-mass spectrometry. Environ. Sci. Pollut. Res. 26, 15458-15466, DOI: 10.1007/s11356-019-04903-x (2019).

32. Greig, E. I., Wood, E. M. \& Bonter, D. N. Winter range expansion of a hummingbird is associated with urbanization and supplementary feeding. Proc. R. Soc. B Biol. Sci. 284, DOI: 10.1098/rspb.2017.0256 (2017).

33. Jepson, W. L. \& Hickman, J. C. The Jepson Manual: Higher Plants of California (University of California Press, Berkeley, 1993).

34. Scarfe, A. \& Finlay, J. C. Rapid second nesting by Anna's Hummingbird near its Northern breeding limit. West. Birds 32, 131-133 (2001).

35. Bibby, C. J., Burgess, N. D. \& Hill, D. A. Bird census techniques (Academic Press, London, 1992).

36. Thogmartin, W. E. et al. A Review of the Population Estimation Approach of the North American Landbird Conservation Plan. Auk 123, 892-904, DOI: 10.1093/auk/123.3.892 (2006).

37. Carter, M. F., Hunter, W. C., Pashley, D. N. \& Rosenberg, K. V. Setting Conservation Priorities for Landbirds in the United States: The Partners in Flight Approach. Auk 117, 541-548, DOI: 10.1093/auk/117.2.541 (2000).

38. Sauer, J. R. \& Link, W. A. Analysis of the North American Breeding Bird Survey Using Hierarchical Models. Auk 128, 87-98, DOI: 10.1525/auk.2010.09220 (2011).

39. Sauer, J. R., Niven, D. K., Pardieck, K. L., Ziolkowski, D. J. \& Link, W. A. Expanding the North American Breeding Bird Survey analysis to include additional species and regions. J. Fish Wildl. Manag. 8, 154-172, DOI: 10.3996/ 102015-JFWM-109 (2017).

40. Smith, A. C. \& Edwards, B. P. M. North American Breeding Bird Survey status and trend estimates to inform a wide range of conservation needs, using a flexible Bayesian hierarchical generalized additive model. Condor 123, 1-16, DOI: 10.1093/ornithapp/duaa065 (2021).

41. Stanton, J. C., Blancher, P., Rosenberg, K. V., Panjabi, A. O. \& Thogmartin, W. E. Estimating uncertainty of north american landbird population sizes. Avian Conserv. Ecol. 14, DOI: 10.5751/ACE-01331-140104 (2019).

42. Schuster, R. et al. Optimizing the conservation of migratory species over their full annual cycle. Nat. Commun. 10, DOI: 10.1038/s41467-019-09723-8 (2019).

43. Johnston, A. et al. Abundance models improve spatial and temporal prioritization of conservation resources. Ecol. Appl. 25, 1749-1756, DOI: 10.1890/14-1826.1 (2015).

44. R Core Team. R: A language and environment for statistical computing (Version 4.0.3) (2020).

45. Smith, A. C., Hudson, M.-A., Aponte, V. \& Francis, C. North American Breeding Bird Survey - Canadian Trends Website, Data-version 2017 (2019).

46. Edwards, B. P. \& Smith, A. C. BbsBayes: An R package for hierarchical bayesian analysis of North American Breeding bird survey data. bioRxiv DOI: 10.1101/2020.05.27.118901 (2020). 


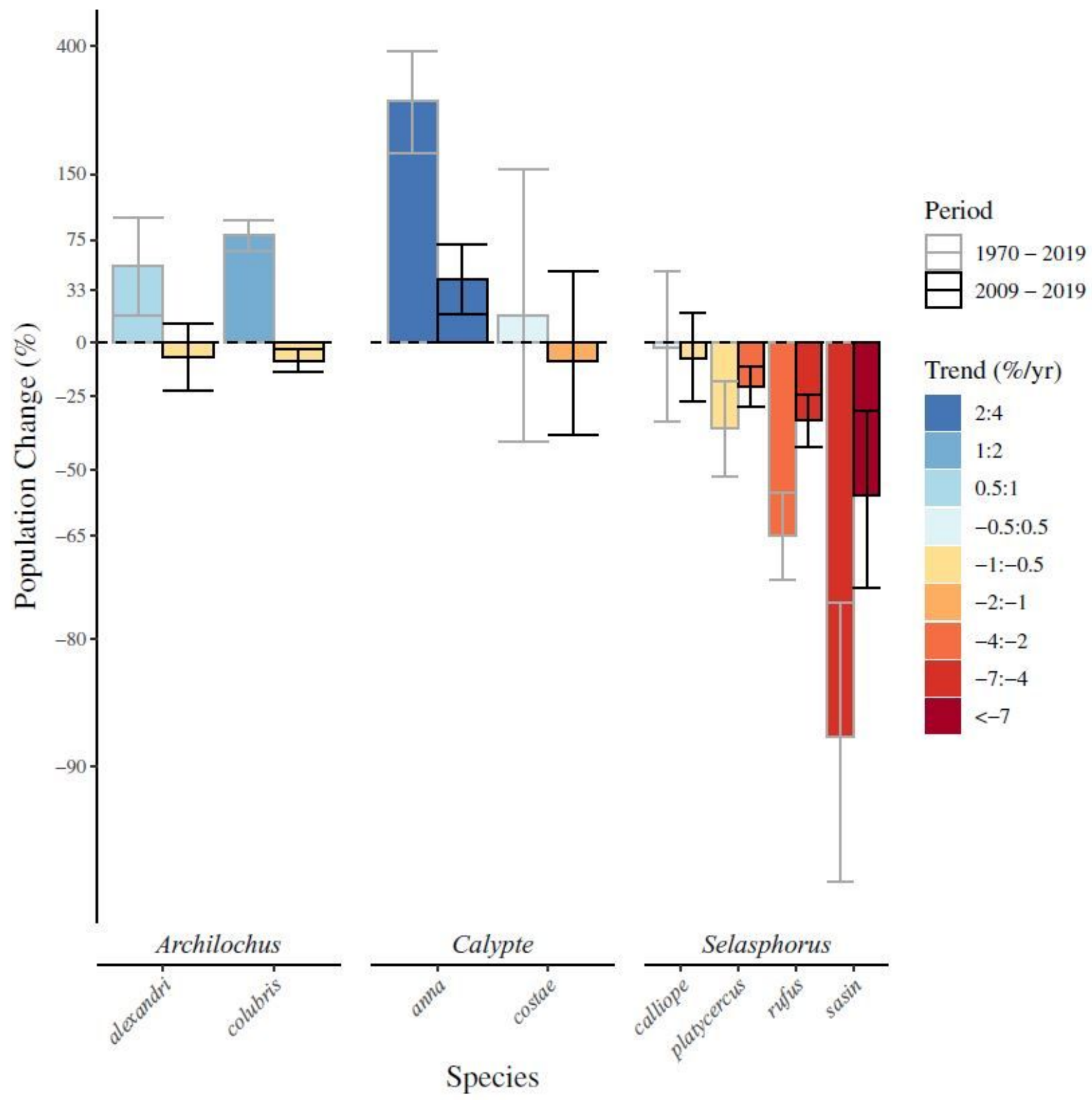

Figure 1

Percent change in hummingbird populations across North America. Vertical axes scale to symmetry on the log-scale to accurately represent the percent change necessary for a population to recover to initial size at the beginning of the period. Column colours scaled to rate of change where darker hues reflect a greater rate of change. Errors shown are the upper and lower bounds of $90 \%$ credible-intervals. 


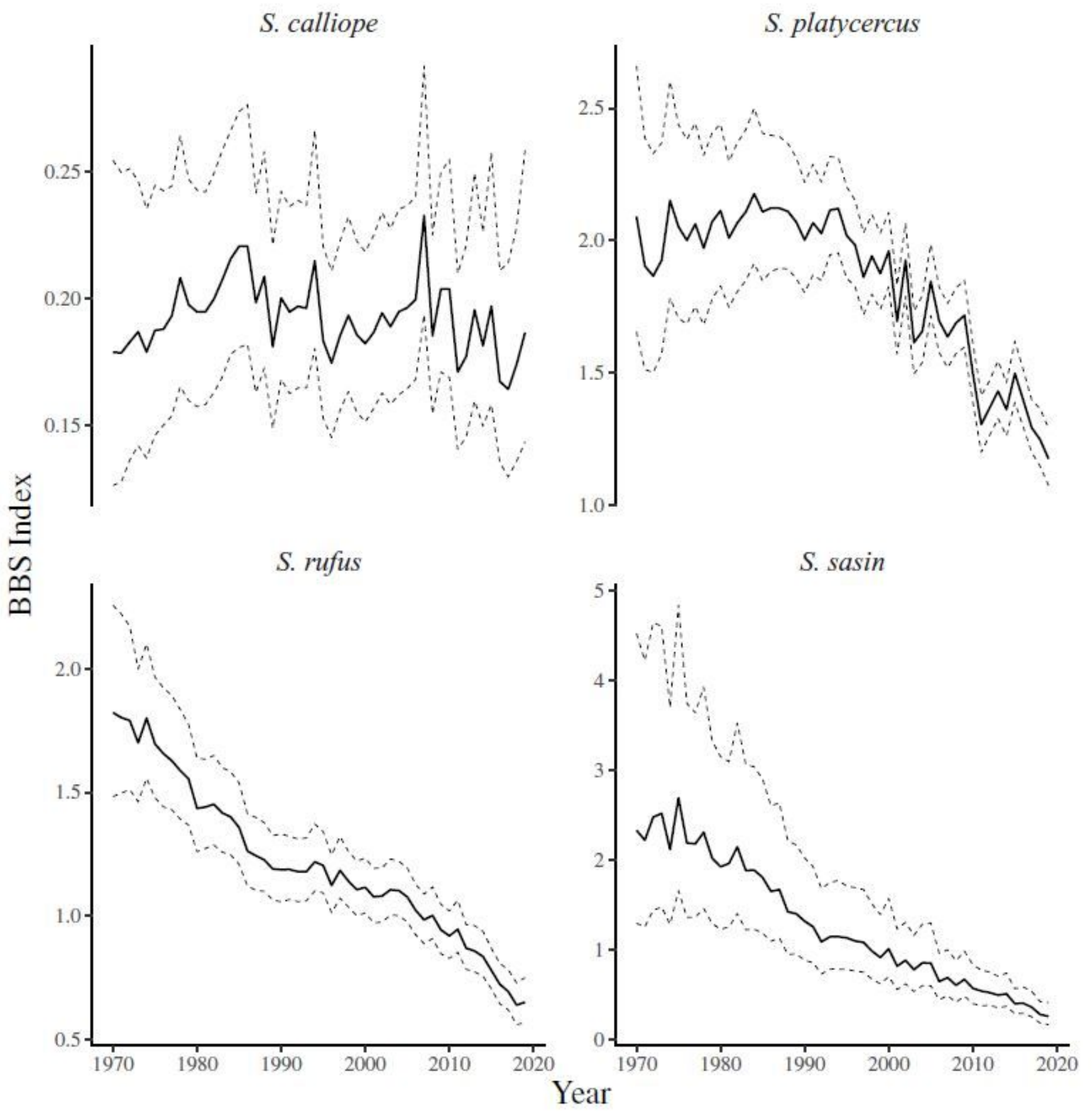

Figure 2

Breeding Bird Survey indices for North American hummingbirds in the Selasphorus genus from 1970 to 2019. Dashed lines represent upper and lower bounds of the $90 \%$ credible-interval. 


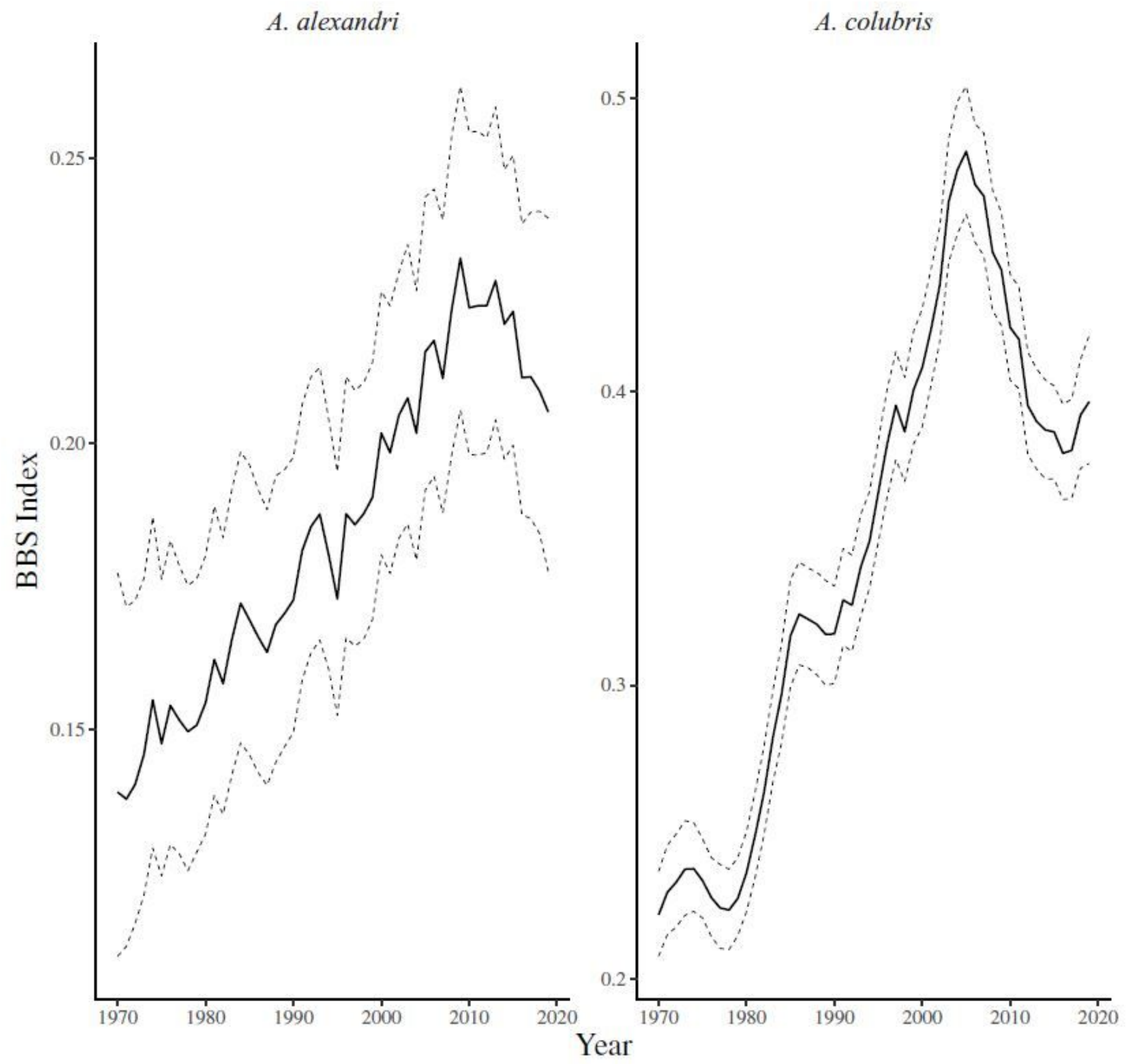

Figure 3

Breeding Bird Survey indices for North American hummingbirds in the Archilochus genus from 1970 to 2019. Dashed lines represent upper and lower bounds of the $90 \%$ credible-interval. 


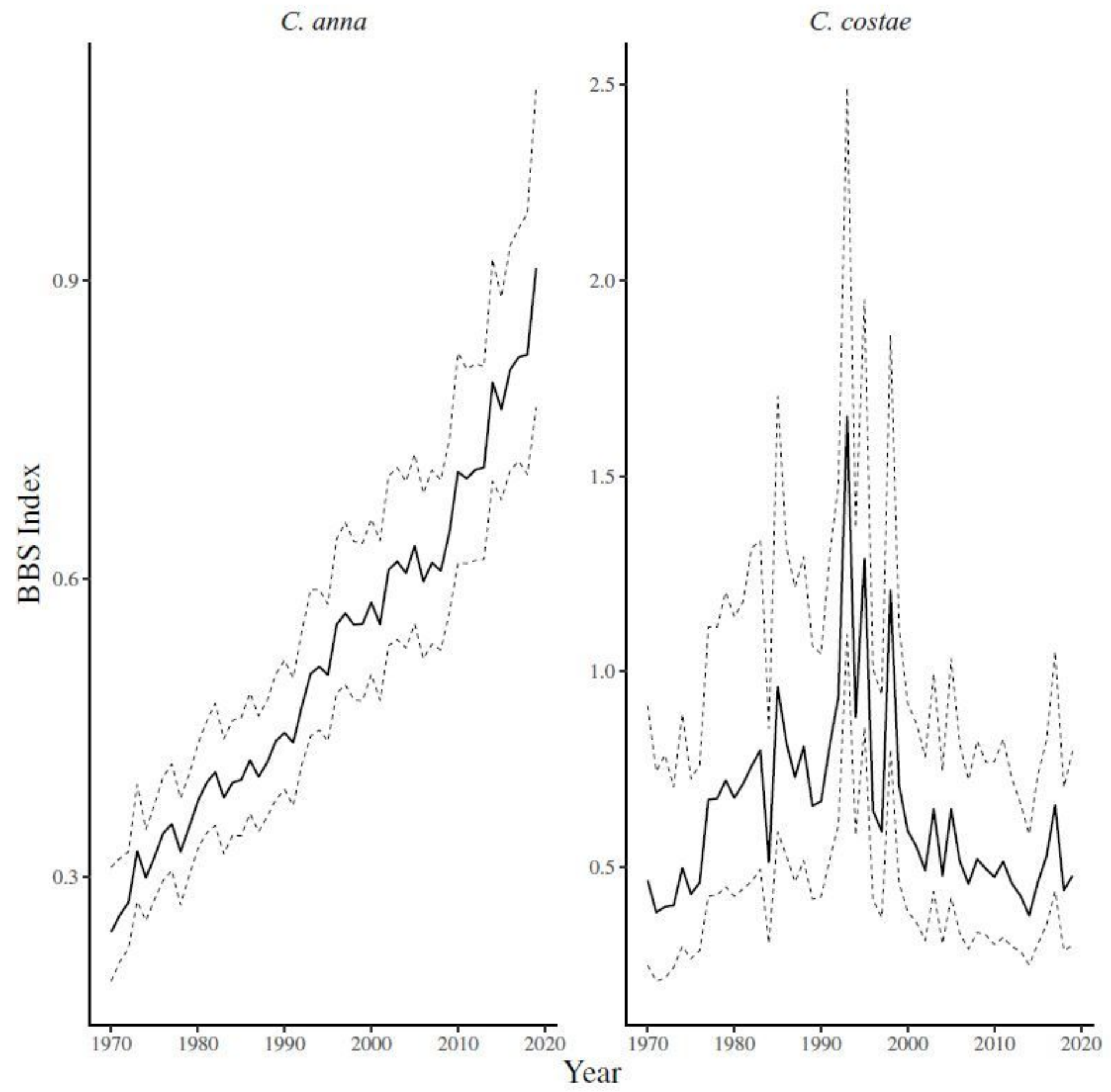

Figure 4

Breeding Bird Survey indices for North American hummingbirds in the Calypte genus from 1970 to 2019. Dashed lines represent upper and lower bounds of the $90 \%$ credible-interval.

\section{Supplementary Files}

This is a list of supplementary files associated with this preprint. Click to download. 
- HummingbirdPopulationTrendssupp.pdf 